\title{
Preparation of Polyimide Films with Ultra-Low Dielectric Constant by Phase Inversion
}

\author{
Panpan Zhang ${ }^{1, *}$, Lize Zhang ${ }^{1}$, Ke Zhang ${ }^{2, *}$, Jiupeng Zhao ${ }^{2}$ and Yao $\mathrm{Li}^{3, *}$ (D) \\ 1 Taiyuan University of Science and Technology, Jincheng Campus, Jincheng 048011, China; \\ 201926050231@stu.tyust.edu.cn \\ 2 MIIT Key Laboratory of Critical Materials Technology for New Energy Conversion and Storage, \\ School of Chemistry and Chemical Engineering, Harbin Institute of Technology, Harbin 150001, China; \\ jpZhao@hit.edu.cn \\ 3 Center for Composite Materials and Structures, Harbin Institute of Technology, Harbin 150001, China \\ * Correspondence: Zpanpan1989@163.com (P.Z.); zhangke@hit.edu.cn (K.Z.); yaoli@hit.edu.cn (Y.L.)
}

Citation: Zhang, P.; Zhang, L.; Zhang, K.; Zhao, J.; Li, Y. Preparation of Polyimide Films with Ultra-Low Dielectric Constant by Phase Inversion. Crystals 2021, 11, 1383. https://doi.org/10.3390/ cryst11111383

Academic Editors: Zhi Lin and Hiroshi Yokoyama

Received: 23 October 2021

Accepted: 11 November 2021

Published: 12 November 2021

Publisher's Note: MDPI stays neutral with regard to jurisdictional claims in published maps and institutional affiliations.

Copyright: () 2021 by the authors. Licensee MDPI, Basel, Switzerland. This article is an open access article distributed under the terms and conditions of the Creative Commons Attribution (CC BY) license (https:// creativecommons.org/licenses/by/ $4.0 /)$.
Abstract: Due to the high value of its dielectric constant, polyimide does not meet the requirements of the development of integrated circuits and high-frequency printed circuits. The development of novel low dielectric constant polyimide materials for the preparation of flexible copper clad laminates is of theoretical and practical significance in the application of polyimide for $5 \mathrm{G}$ communications. In this work, different fluorinated graphene/polyamic acids (FG/PAA) were used as the precursor, and the porous polyimide film was successfully prepared by phase inversion. The dielectric constant of the porous polyimide film is relatively low, being less than 1.7. When the content of fluorinated graphene is $0.5 \mathrm{wt} \%$, the overall dielectric performance of the porous film is the best, with a dielectric constant of $1.56(10 \mathrm{kHz})$ and a characteristic breakdown field strength of $56.39 \mathrm{kV} / \mathrm{mm}$. In addition, the mechanical properties of the film are relatively poor, with tensile strengths of $13.87 \mathrm{MPa}$ $(0.2 \mathrm{wt} \%), 13.61 \mathrm{MPa}(0.5 \mathrm{wt} \%)$, and $6.25 \mathrm{MPa}(1.0 \mathrm{wt} \%)$, respectively. Therefore, further improving the breakdown resistance and mechanical properties of the porous film is essential for the application of porous ultra-low dielectric polyimide materials.

Keywords: polyimide; phase inversion; dielectric constant; porous films

\section{Introduction}

Flexible printed circuits (FPC) have been widely used in sophisticated electronic products because of their outstanding characteristics, such as having a light weight, thin structure, and good bending. With the arrival of the $5 \mathrm{G}$ era, electronic products are developing in the direction of high-frequency and high-speed digital signal transmission, and the demand for high-frequency and high-speed FPC as the carrier of signal transmission is increasing. Previous research has indicated that reducing the dielectric constant of the materials used in the dielectric layer of the substrate is the most effective and direct way to improve the transmission speed and efficiency of microelectronic devices and promote the high-frequency and high-speed development of the FPC. Moreover, polyimide has long been used for the interconnection between metals in electronic devices as an excellent insulating dielectric layer owing to outstanding mechanical and heat-resistant properties [1,2]. However, polyimide films, restricted by high dielectric constant (3.1 3.5) [3], have not been able to meet the requirements for the rapid development of modern integrated circuits and high-frequency circuits [4-7]. Therefore, the low dielectric modification of polyimide has become one hot topic in the field of high-frequency and high-speed signal transmission. The development of new low-dielectric polyimide materials for the preparation of flexible copper clad laminate (FCCL) has great theoretical and practical significance for the development and application of polyimide in the field of $5 \mathrm{G}$ communication. 
For polyimide materials, there are mainly two methods to reduce the dielectric constant: (1) reducing the material polarizability by introducing fluorine atom or lipid ring structure [8-14], and (2) reducing the number of polarizing molecules per unit volume by constructing a large skeleton structure to increase the free volume or by introducing air in the structure [15-20]. Since the intrinsic dielectric constant of air is extremely low, the dielectric constant of the material can be significantly reduced by injecting air into the polyimide system. Besides, introducing air into the material itself, thereby preparing a pore-containing structure to reduce its dielectric constant, is also the most direct way currently known [21]. In particular, the phase inversion method has been widely used in the preparation of asymmetric porous polyimide films due to its simplicity and high flexibility [22-25].

On this basis, the phase inversion method was used in this work to prepare porous polyimide films with ultra-low dielectric constant, and the influence of precursor composition (fluorated graphene/polyamide acid) on the morphology, structure, dielectric, and mechanical properties of the porous films was further investigated.

\section{Experiments}

2.1. Raw Materials

Raw materials: 4,4'-diamino diphenyl ether (99\%, AR, Beijing Bailingwei Science and Technology Co., Ltd., Beijing, China), 3,3',4,4'-BTDA (96\%, AR, Shanghai Aladdin Biological Technology Co., Ltd., Shanghai, China), N,N-dimethyl acetamide (99.5\%, AR, Tianjin Guangfu Fine Chemical Research Institute, Tianjin, China), fluorated graphene (CF0.61, AR, Shanghai Fubang Chemical Co., Ltd., Shanghai, China), and ultrapure water ( $\mathrm{RO}>18 \mathrm{M} \Omega / \mathrm{cm}$, homemade).

\subsection{Preparation Routes of Porous PI Films}

Firstly, polyamidoic acid hybrid precursors with FG content of $0.2 \mathrm{wt} \%, 0.5 \mathrm{wt} \%$, and $1.0 \mathrm{wt} \%$ were prepared by using the traditional solution blending method [12]. Secondly, the porous film was obtained by the phase transformation method. Specifically, the precursor film was coated on the glass plate and then fully exchanged in a water bath at $0{ }^{\circ} \mathrm{C}$ to form the porous polyamido acid film. Thirdly, the porous polyamide acid films were placed in a vacuum at $60^{\circ} \mathrm{C}$ for $2 \mathrm{~h}$ to remove the excess solvent and water. Three kinds of porous polyimide films with FG content of $0.2 \mathrm{wt} \%, 0.5 \mathrm{wt} \%$, and $1.0 \mathrm{wt} \%$ in the precursors were obtained after the porous polyimide films were subjected to thermal imidization at $100{ }^{\circ} \mathrm{C}$, $200{ }^{\circ} \mathrm{C}$, and $300^{\circ} \mathrm{C}$ for $1 \mathrm{~h}$, respectively. Finally, the porous polyimide films were peeled off by soaking the glass plate in hot water for some time. Figure 1 shows the formation mechanism of the porous polyimide films.

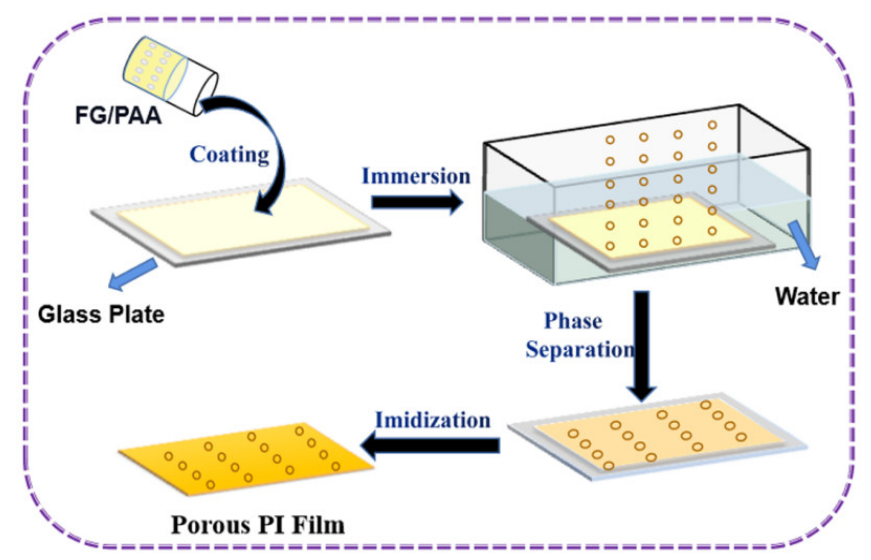

Figure 1. Schematic diagram for the formation mechanism of porous PI films. 


\subsection{Examination and Characterization}

In this paper, the morphology and internal mechanism of the films were observed by Quanta 200FEG scanning electron microscope from America. The structure analysis of the films was conducted by a X-ray diffractometer (XRD) from Japan (Rigaku Dmax-rB, Rigaku Corporation, Tokyo, Japan) and a Fourier transform infrared spectrometer (FTIR) from the United States (Nicolet Avatar-360, Thermo Nicolet Corporation, Waltham, MA, USA). Then, the mechanical tensile test of the films was performed using the tester (WDW20, Jinan Fangyuan Testing Machine Co., Ltd., Jinan, China). Afterward, the dielectric spectrum and breakdown performance of the films were examined with an impedance analyzer (Agilent4294A, Agilent Technologies Corporation, Santa Clara, CA, USA) and the breakdown voltage test system (YD2013, Changzhou Yangzi Electronic Co., Ltd., Changzhou, China). Dynamic mechanical analysis (DMA) was performed on a sample size of $30 \times 5 \times 0.5 \mathrm{~mm}^{3}$ using a TA Instruments dynamic mechanical analyzer (DMAQ 800, TA Instruments Corporation, Newcastle, DE, USA). The stretch film mode was carried out in the ambient temperature range up to $200{ }^{\circ} \mathrm{C}(1 \mathrm{~Hz})$ with a heating ratio of $5{ }^{\circ} \mathrm{C} / \mathrm{min}$. Thermal analysis (TGA) was performed using a thermal analyzer (TG/DTA 6300, Seiko Corporation of Japan, Osaka, Japan) under a nitrogen flow rate, with a heating rate of $10^{\circ} \mathrm{C} \cdot \mathrm{min}^{-1}$.

\section{Results and Discussion}

\subsection{Structure of PI Films}

The basic structures of three kinds of porous films were characterized by FT-IR. As illustrated in Figure 2, the porous films had significant characteristic absorption peaks at $718 \mathrm{~cm}^{-1}, 1376 \mathrm{~cm}^{-1}, 1719 \mathrm{~cm}^{-1}$, and $1780 \mathrm{~cm}^{-1}$, which represented the bending vibration, the stretching vibration absorption, the symmetric stretching vibration, and the asymmetric stretching vibration of $\mathrm{C}=\mathrm{O}$ bond, respectively. They were all characteristic peaks of polyimides. This confirmed that the porous polyamides had been converted to polyimides, and the presence of fluorinated graphene had no impact on the thermal imidization transition of porous films [12].

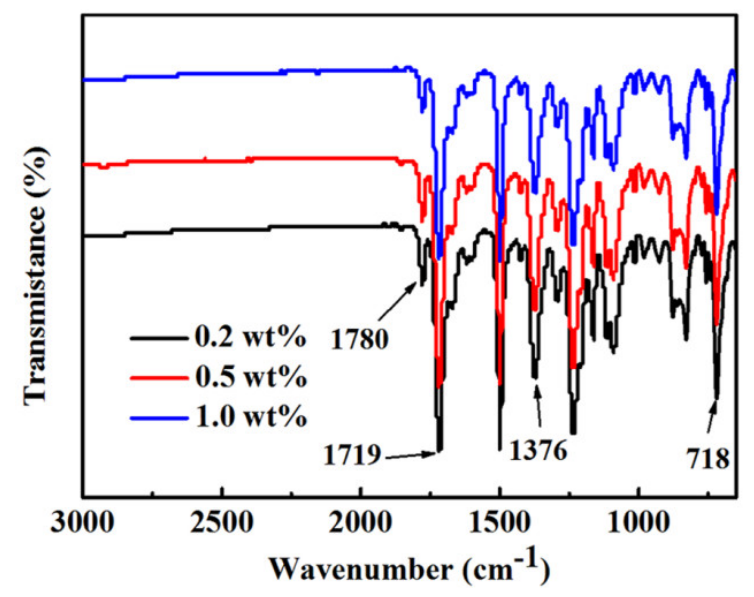

Figure 2. FT-IR spectra of porous PI films.

The internal structures of the three kinds of porous films were further analyzed by X-ray diffraction spectroscopy (XRD). As exhibited in Figure 3, the porous films had a typical steamed bread broad peak, with a range of $2 \theta=16 \sim 19^{\circ}$. This indicated that the prepared porous film was overall amorphous while there might be locally ordered regions inside. Moreover, the diffraction peaks of the three kinds of films were slightly different due to the differences between the pore structure inside the film and the ordered region. 


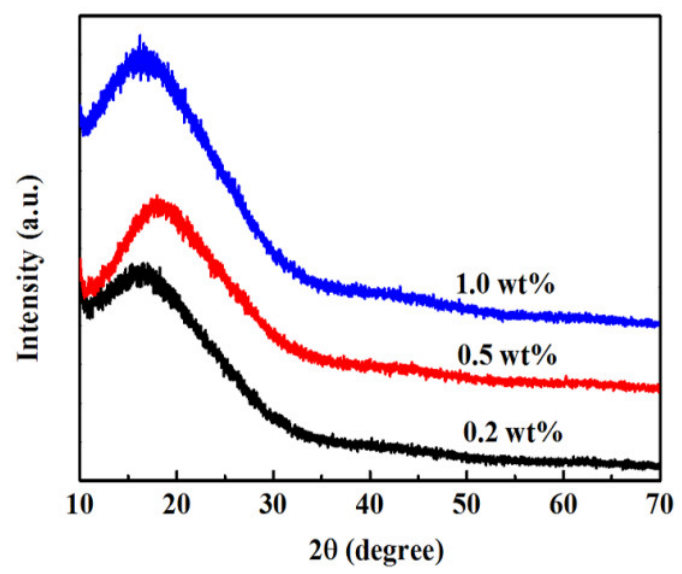

Figure 3. XRD patterns of porous PI films.

\subsection{Morphology of Porous PI Films}

The SEM images of the surface and cross-section after brittle fracture of the porous film are presented in Figure 4. As illustrated in a1-c1 at the far left of Figure 4, the cross-sections of different films were significantly different. For a1, with the smallest doping content, the pores in the film were relatively loose and mainly constituted by irregular circular pores and elliptical pores. With the increase in FG doping content, the pores in the film became more concentrated, dominated by strip pores. The film presented irregular long pores when the content of FG in the precursors was $1.0 \mathrm{wt} \%$. Moreover, the pore structure inside the three kinds of films was different from that of the porous polyimides obtained by the traditional phase transformation method. This can be explained that the presence of FG in the precursors affected not only the diffusion between solvent and non-solvent to some extent but also the formation of the whole pore structure. Besides, SEM images of the lower surface and upper surface of the porous film are exhibited in Figure $4 a_{2}-c_{2}, a_{3}-c_{3}$, respectively. Compared with the upper surface containing pores, the lower surface of the three kinds of films was relatively compact and had no particularly obvious pores. This was mainly because the phase transfer process was initially generated on the upper surface, slowing down and hindering the formation and expansion of pores in the film from top to bottom.
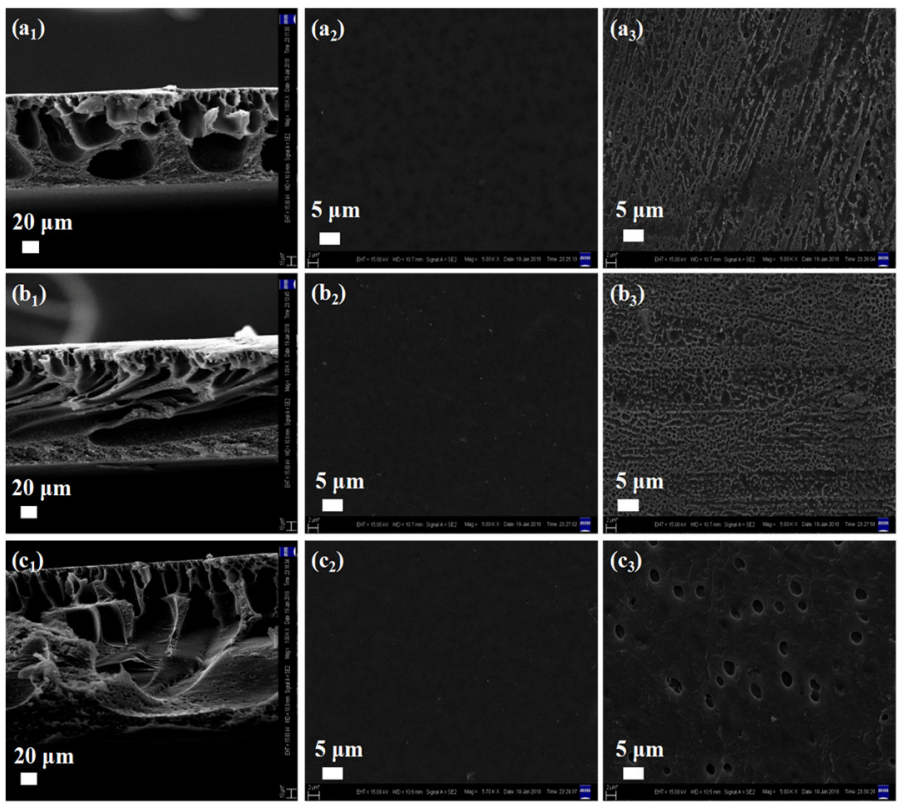

Figure 4. Morphology of cross section $\left(\mathbf{a}_{1}-\mathbf{c}_{1}\right)$, bottom surface $\left(\mathbf{a}_{2}-\mathbf{c}_{2}\right)$ and top surface $\left(\mathbf{a}_{3}-c_{3}\right)$ of porous PI films: (a) $0.2 \mathrm{wt} \%$, (b) $0.5 \mathrm{wt} \%$, (c) $1.0 \mathrm{wt} \%$. 


\subsection{Analysis of Dielectric Properties}

The dielectric-frequency spectra of different polyimide porous films at room temperature are provided in Figure 5. Figure 5a-c represent the test curves of the film's dielectric constant, dielectric loss, and electrical conductivity changing with the frequency, respectively. In Figure 5a, similar to the porous film without FG [18], the dielectric constant of the three kinds of porous films decreased slightly with the increase of the frequency because the dipole direction gradually could not keep up with the changes with the increase in the electric field, resulting in a low effective polarization and a decrease in the dielectric constant. For the porous films prepared by polyamidoic acid composite precursor system with different FG contents, the dielectric constant was $1.63(1.0 \mathrm{wt} \%), 1.62(0.2 \mathrm{wt} \%)$, and $1.56(0.5 \mathrm{wt} \%)$ in a decreasing order when the frequency was $10 \mathrm{kHz}$. The ultra-low dielectric constants of polyimide porous films are probably mainly due to the introduction of air and $\mathrm{F}$ atoms. Meanwhile, the dielectric constant of porous polyimide film was the minimum when the FG content in the precursors was $0.5 \mathrm{wt} \%$, similar to the FG modified polyimide film [12]. This might be mainly because the overall pore structure (porosity and pore size distribution) and intensity polarization of the polyimide film itself was the optimum when the FG doping ratio reached $0.5 \mathrm{wt} \%$. As illustrated in Figures $4 \mathrm{c}$ and $5 \mathrm{~b}$, the dielectric loss and conductivity of the film were relatively small. The dielectric losses of the three kinds of films had better stability in a wider frequency range $\left(10^{3} \sim 10^{6} \mathrm{~Hz}\right)$, and the loss value was less than 0.004 , since the introduction of fluorine element reduced the overall polarizability of the films. Moreover, the conductivity of the three kinds of films was lower than $10^{-8} \mathrm{~S} / \mathrm{m}(10 \mathrm{kHz})$, indicating that the porous films still had excellent dielectric properties.
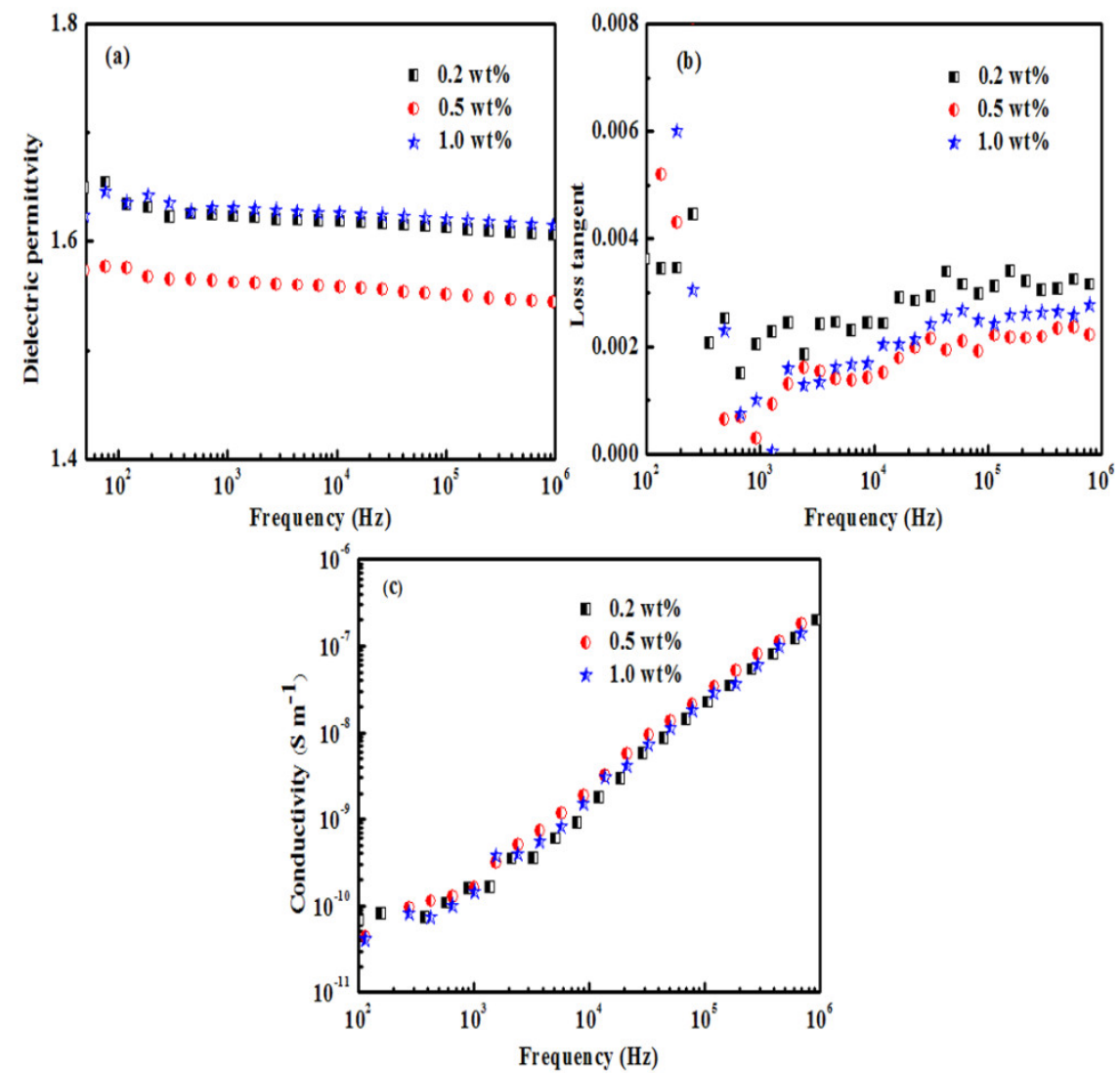

Figure 5. Dielectric properties of the different porous PI films: (a) dielectric constant, (b) loss tangent, (c) conductivity. 
The Weibull function was used to conduct a mathematical analysis on the breakdown field strength of porous polyimide films, and the detailed expression is [18]:

$$
P(E)=1-e^{-(E / \alpha)^{\beta}}
$$

where $P(E)$ denotes the cumulative failure probability; $E$ represents the breakdown test field strength data of a sample; $\beta$ indicates the shape factor of the fitting; $\alpha$ refers to the characteristic breakdown field strength (the electric field strength when the cumulative failure probability of the sample reaches 63.2\%). After taking the logarithm of Equation (1) twice, it can be expressed as:

$$
\ln (-\ln (1-P(E)))=\beta \ln E-\beta \ln \alpha
$$

According to Equation (2), a straight line was made with $\ln (-\ln (1-P(E)))$ and $\ln E$ as the vertical and abscess coordinates, respectively. The magnitude of $\alpha$ and $\beta$ could be obtained from the intercept and slope of the line using the least square method, respectively. The pictorial diagram of the Weibull distribution of the breakdown strength of three kinds of porous films is presented in Figure 6. Their detailed fitting parameters are listed in Table 1. As observed from the table, the linear correlation coefficient $\mathrm{R}$ of the porous film was greater than 0.95 , demonstrating that the breakdown test data could well obey the Weibull distribution. Besides, it is revealed from the Figure that the characteristic breakdown strength $\alpha$ of the three kinds of films was $61.98 \mathrm{kV} / \mathrm{mm}(0.2 \mathrm{wt} \%), 56.39 \mathrm{kV} / \mathrm{mm}(0.5 \mathrm{wt} \%)$, and $34.95 \mathrm{kV} / \mathrm{mm}(1.0 \mathrm{wt} \%)$ in turn. The differences in the breakdown strength of the three kinds of porous films were primarily caused by the films' different internal pore structures and defects. In addition, it can be seen that compared with the polyimide film without pores, the breakdown strength of porous films has dropped a lot [26], which is mainly due to the increase of defects caused by the introduction of pores.

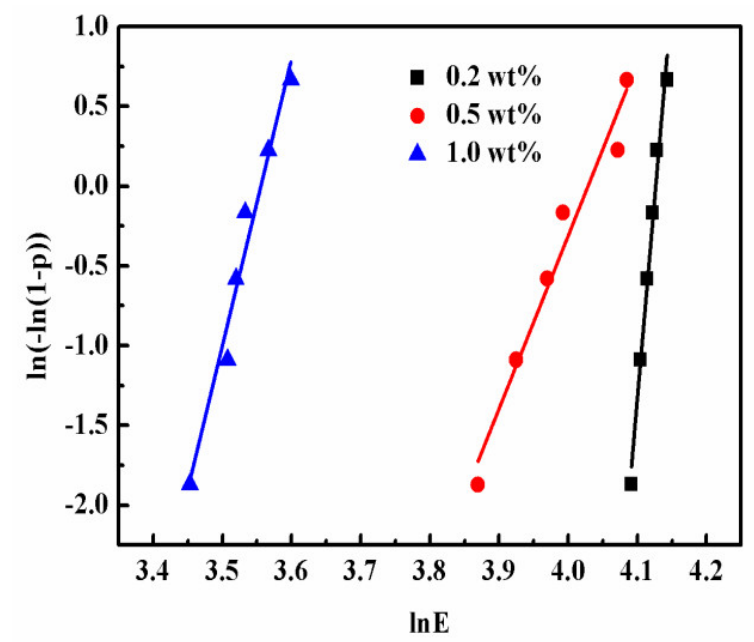

Figure 6. Weibull distribution of the different porous PI films.

Table 1. Fitting data and Weibull distribution parameters of porous PI films.

\begin{tabular}{cccccc}
\hline \multirow{2}{*}{ PI Films } & \multicolumn{3}{c}{ Linear Fitting Results } & \multicolumn{2}{c}{ Weibull Parameters } \\
\cline { 2 - 6 } & Slope & $\boldsymbol{\operatorname { l n } ( - \operatorname { l n } ( \mathbf { 1 } - \boldsymbol { P } ( \boldsymbol { E } ) ) \text { Intercept }}$ & $\mathbf{R}$ & $\boldsymbol{\beta}$ & $\boldsymbol{\alpha} / \mathbf{k V m m}^{-\mathbf{1}}$ \\
\hline $0.2 \mathrm{wt} \%$ & 50.09 & -206.71 & 0.9822 & 50.09 & 61.98 \\
\hline $0.5 \mathrm{wt} \%$ & 10.84 & -43.71 & 0.9589 & 10.84 & 56.39 \\
\hline $1.0 \mathrm{wt} \%$ & 18.00 & -63.97 & 0.9615 & 18.00 & 34.95 \\
\hline $\begin{array}{c}\text { Nonporous } \\
{[26]}\end{array}$ & 9.68 & -59.74 & 0.9702 & 9.68 & 478.90 \\
\hline
\end{tabular}




\subsection{Analysis of Tensile Properties}

A tensile test chart of porous films is illustrated in Figure 7. Figure 7a-c represents the tensile strength, tensile modulus, and elongation at break, respectively. Specifically, the mechanical properties of porous polyimide films with FG content of $0.2 \mathrm{wt} \%$ and $0.5 \mathrm{wt} \%$ in the precursors were similar. When FG content was $0.2 \mathrm{wt} \%$, the tensile strength and modulus were $13.87 \mathrm{MPa}$ and $0.84 \mathrm{GPa}$, respectively. When FG content was $0.5 \mathrm{wt} \%$, the strength and modulus of the porous film were $13.61 \mathrm{MPa}$ and $0.61 \mathrm{GPa}$, respectively. However, the mechanical strength of the porous polyimide material significantly decreased when the composite ratio of FG in the precursors reached $1.0 \mathrm{wt} \%$. According to the above SEM images, this might be caused by the disorder of the pores in the material and the increase of defects. Moreover, the overall tensile properties of the three kinds of porous polyimides were not preferable compared with nonporous polyimides because of the increase of overall defects in the films caused by the existence of internal pores.

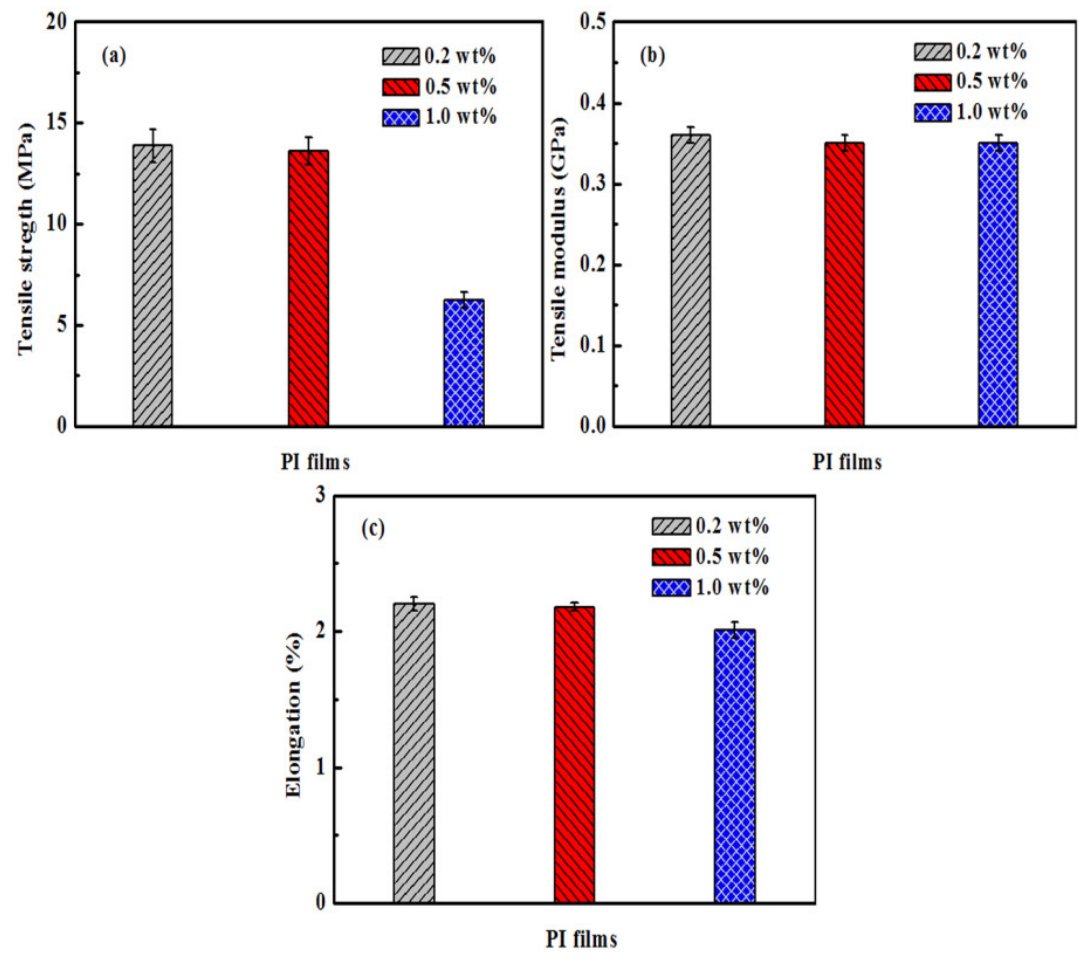

Figure 7. Tensile performance of the porous PI films: (a) tensile strength, (b) tensile modulus, (c) elongation at break.

\subsection{Analysis of Thermal Properties}

The thermal performance test results of polyimide films are shown in Figure 8. It is clear that the glass transition temperature of porous films is lower than that of nonporous PI films. Moreover, as the FG content increases, the glass transition temperature of the film decreases. This phenomenon may be mainly due to the increase of internal pores in the polyimide films. However, it can be noticed from Figure and illustration that the glass transition temperature of porous film $(0.5 \mathrm{wt} \%)$ is higher than $275^{\circ} \mathrm{C}$ and the thermal decomposition temperature at $5 \mathrm{wt} \%$ weight loss is higher than $550{ }^{\circ} \mathrm{C}$, which is mainly attributed to the excellent thermal stability of the polyimide matrix. 


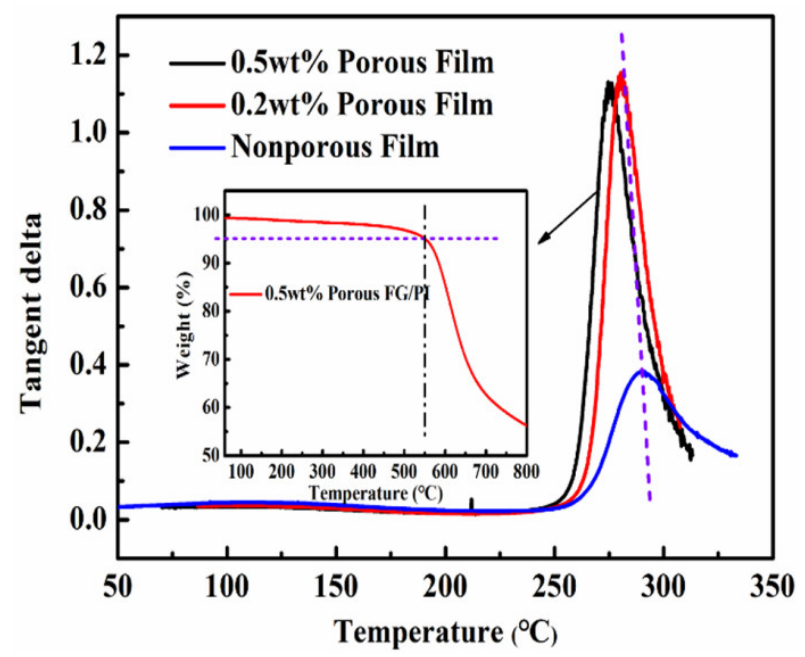

Figure 8. Thermal properties of PI films.

\section{Conclusions}

The phase inversion method was employed to successfully prepare porous polyimide films with fluorinated graphene/polyamidoic acid as precursor reagents. The pore structure of the films was significantly different from that of traditional porous polyimides due to the existence of fluorated graphene. The polyimide porous films with an ultra-low dielectric constant were obtained. The dielectric constant of the porous film was $1.56(10 \mathrm{kHz})$ when the content of fluorated graphene in the precursor reagents was $0.5 \mathrm{wt} \%$ due to the optimal effective porosity and overall polarization effect. The breakdown resistance and mechanical properties of porous films were low. For the three kinds of porous films (FG content: $0.2 \mathrm{wt} \%, 0.5 \mathrm{wt} \%$, and $1.0 \mathrm{wt} \%$ ), the breakdown field strength was $61.98 \mathrm{kV} / \mathrm{mm}$, $56.39 \mathrm{kV} / \mathrm{mm}$, and $34.95 \mathrm{kV} / \mathrm{mm}$, respectively, and the tensile strength was $13.87 \mathrm{MPa}$, $13.61 \mathrm{MPa}$, and $6.25 \mathrm{MPa}$, respectively. Therefore, further improving the breakdown resistance and mechanical properties of the porous films by introducing reinforcing layers or optimizing the pore structure is of great significance for the development and application of porous and low-dielectric polyimide materials.

Author Contributions: Conceptualization, P.Z. and Y.L.; methodology, K.Z., J.Z. and P.Z.; software, P.Z.; validation, P.Z., K.Z. and L.Z.; formal analysis, P.Z.; investigation, P.Z.; resources, Y.L. and J.Z.; data curation, P.Z.; writing—original draft preparation, P.Z. and K.Z.; writing—review and editing, P.Z., K.Z., J.Z. and L.Z. All authors have read and agreed to the published version of the manuscript.

Funding: This research received no external funding.

Data Availability Statement: Not applicable.

Acknowledgments: We appreciate the financial support of the Collaborative Innovation Center of Internet+3D Printing from Shanxi Province (CiCi3DP). This work was supported by the Scientific Research Foundation of Taiyuan University of Science and Technology (No.20182056, 20192009), the Natural Science Foundation for Young Scientists of Shanxi Province (No.201901D211308), the Scientific and Technological Innovation Programs of Higher Education Institutions of Shanxi Province (No.2019L0652), and the College Students' Innovative Entrepreneurial Training Plan Program of Shanxi Province (No.20210508).

Conflicts of Interest: The authors declare no conflict of interest.

\section{References}

1. Maier, G. Low dielectric constant polymers for microelectronics. Prog. Polym. Sci. 2001, 26, 3-65. [CrossRef]

2. Yang, M.H. The Dielectrics Characteristics of Base Materials for High Frequency Printed Circuit Boards and the Progress in Modification. Printed. Circuit. Inf. 2009, 4, 27-31. (In Chinese)

3. Maex, K.; Baklanov, M.R.; Shamiryan, D.; Lacopi, F.; Brongersma, S.H.; Yanovitskaya, Z.S. Low dielectric constant materials for microelectronics. J. Appl. Phys. 2003, 93, 8793-8841. [CrossRef] 
4. Ghosh, M. Polyimides: Fundamentals and Applications; Marcel Dekker Press: New York, NY, USA, 1996; p. 471. ISBN 0-8247-9466-4.

5. Mittal, K.L. Polyimides: Synthesis, Characterization and Applications; Springer Science \& Business Media Press: New York, NY, USA, 1982; p. 537. ISBN 978-1-4615-7639-6.

6. Stenzenberger, H.D.; Hergenrother, P.M. Polyimides; Springer Science \& Business Media Press: New York, NY, USA, 1990 ; p. 34. ISBN 978-94-010-9663-8.

7. Volksen, W.; Miller, R.D.; Dubois, G. Low Dielectric Constant Materials. Chem. Rev. 2010, 110, 56-110. [CrossRef] [PubMed]

8. Meador, M.; Mcmillon, E.; Anna, S.; Barrios, E.; Wilmoth, N.G.; Mueller, C.H.; Miranda, F.A. Dielectric and Other Properties of Polyimide Aerogels Containing Fluorinated Blocks. ACS. Appl. Mater. Interfaces 2014, 6, 6062-6068. [CrossRef] [PubMed]

9. Wu, T.; Dong, J.; Gan, F.; Fang, Y.; Zhao, X.; Zhang, Q. Low dielectric constant and moisture-resistant polyimide aerogels containing trifluoromethyl pendent groups. Appl. Surf. Sci. 2018, 440, 595-605. [CrossRef]

10. Catalin-Paul, C.; Damaceanu, M.; Varganici, C.; Wolinska-Grabczyk, A.; Bruma, M. Dielectric and gas transport properties of highly fluorinated polyimides blends. High. Perform. Polym. 2015, 27, 526-538.

11. Li, Q.; Wang, Y.; Zhang, S.; Pang, L.; Tong, H.; Li, J.; Xu, Z. Novel fluorinated random co-polyimide/amine-functionalized zeolite MEL50 hybrid films with enhanced thermal and low dielectric properties. J. Mater. Sci. 2017, 52, 5283-5296. [CrossRef]

12. Zhang, P.; Zhao, J.; Zhang, K.; Bai, R.; Wang, Y.; Hua, C.; Liu, X.; Xu, H.; Li, Y. Fluorographene/polyimide composite films: Mechanical, electrical, hydrophobic, thermal and low dielectric properties. Compos. Part A Appl. S. 2016, 84, 428-434. [CrossRef]

13. Wang, Z.; Fang, G.; He, J.J.; Yang, H.X.; Yang, S.Y. Semi-aromatic thermosetting polyimide resins containing alicyclic units for achieving low melt viscosity and low dielectric constant. React. Funct. Polym. 2020, 146, 104411. [CrossRef]

14. Zhang, P.; Zhang, K.; Chen, X.; Dou, S.; Zhao, J.; Li, Y. Mechanical, dielectric and thermal properties of polyimide films with sandwich structure. Compos. Struct. 2021, 261, 113305. [CrossRef]

15. Wang, W.C.; Vora, R.; Kang, E.T.; Neoh, K.G.; Ong, C.K.; Chen, L.F. Nanoporous Ultra-Low-k Films Prepared from Fluorinated Polyimide with Grafted Poly(acrylic acid) Side Chains. Adv. Mater. 2003, 16, 54-57. [CrossRef]

16. Lv, P.; Dong, Z.; Dai, X.; Wang, H.; Qiu, X. Synthesis and properties of ultralow dielectric porous polyimide films containing adamantan. J. Polym. Sci. Pol. Chem. 2017, 56, 549-559. [CrossRef]

17. Hong, Z.; Dongyang, W.; Yong, F.; Hao, C.; Yusen, Y.; Jiaojiao, Y.; Liguo, J. Dielectric properties of polyimide/SiO2 hollow spheres composite films with ultralow dielectric constant. Mater. Sci. Eng. B 2016, 203, 13-18. [CrossRef]

18. Zhang, P.; Zhao, J.; Zhang, K.; Wu, Y.; Li, Y. Effect of co-solvent on the structure and dielectric properties of porous polyimide membranes. J. Phys. D Appl. Phys. 2018, 51, 215305. [CrossRef]

19. Chen, W.; Zhou, Z.; Yang, T.; Bei, R.; Zhang, Y.; Liu, S.; Chi, Z.; Chen, X.; Xu, J. Synthesis and properties of highly organosoluble and low dielectric constant polyimides containing non-polar bulky triphenyl methane moiety. React. Funct. Polym. 2016, 108, 71-77. [CrossRef]

20. Zhang, P.; Zhang, K.; Chen, X.; Dou, S.; Zhao, J.; Li, Y. Influence of Coagulation Bath Temperature on the Structure and Dielectric Properties of Porous Polyimide Films in Different Solvent Systems. ACS. Omega. 2020, 5, 29889-29895. [CrossRef] [PubMed]

21. Miller, R.D. In Search of low-K dielectrics. Science 1999, 286, 421. [CrossRef]

22. Kawakami, H.; Mikawa, M.; Nagaoka, S. Formation of surface skin layer of asymmetric polyimide membranes and their gas transport properties. J. Membr. Sci. 1997, 137, 241-250. [CrossRef]

23. Kim, J.H.; Min, B.R.; Won, J.; Park, H.C.; Kang, Y. Phase behavior and mechanism of membrane formation for polyimide/DMSO/water system. J. Membr. Sci. 2001, 187, 47-55. [CrossRef]

24. Ren, J. Membrane structure control of BTDA-TDI/MDI (P84) co-polyimide asymmetric membranes by wet-phase inversion process. J. Membr. Sci. 2004, 241, 305-314. [CrossRef]

25. Kim, S.; Jang, K.; Choi, H.D.; Choi, S.H.; Kwon, S.J.; Kim, I.D.; Lim, J.A.; Hong, J.M. Porous Polyimide Membranes Prepared by Wet Phase Inversion for Use in Low Dielectric Applications. Int. J. Mol. Sci. 2013, 14, 8698-8707. [CrossRef] [PubMed]

26. Zhang, P.; Zhang, K.; Dou, S.; Zhao, J.; Yan, X.; Li, Y. Mechanical, Dielectric, and Thermal Attributes of Polyimides Stemmed Out of 4,4'-Diaminodiphenyl Ether. Crystals 2020, 10, 173. [CrossRef] 